\title{
Influence of Preform Interlacement on the Low Velocity Impact Behavior of Multilayer Textile Composites
}

\author{
NaVEen V. Padaki \\ Regional Silk Technological Research Station, CSTRI, Central Silk \\ Board, Muga Farm, Khanapara, Guwahati-781022, India \\ R. AlagirusamY* AND B. L. DeOPURA \\ Department of Textile Technology, Indian Institute of \\ Technology-Delhi, Hauz Khas, New Delhi-110 016, India \\ RAUL FANGUEIRO \\ Department of Textile Engineering, University of Minho, \\ Guimaraes - 4800058, Portugal
}

\begin{abstract}
Impact property of composite material is influenced not only by the type of fiber/matrix, but also by the woven structure of the reinforcement. Presence of $3 \mathrm{D}$ fibers in reinforcement is reported to enhance the performance of textile composites in an impact event. This article attempts to study the influence of interlacements in the multilayer woven interlocked 3D structures on the impact properties of the composite material reinforced with them. Low velocity impact testing was carried out on an instrumented drop weight impact tester to obtain loadelongation-time plots of the impact event. It has been observed that increased interlacement in the structure improves the impact resistance of the multilayer textile composites. Further, damage area maps have been developed to understand and analyze the interlacement effect on the impact behavior.
\end{abstract}

KEY WORDS: multilayer woven interlocked structures, interlacement index, low velocity impact behavior, damage area analyses.

*Author to whom correspondence should be addressed. E-mail: alagiru@gmail.com Figures 1, 2 and 5-7 appear in color online: http://jit.sagepub.com 


\section{INTRODUCTION}

$\mathbf{T}$

EXTILE STRUCTURES ARE preferred materials used for reinforcement in composite applications due to their uniqueness like handling, shapability, adaptability, and structural complexity [1]. Low velocity drop weight impact property of textile composites is a vital dynamic trait with respect to composites performance. Recent articles addressing the low velocity impact behavior of fiber reinforced composites point to susceptibility of these materials to localized impact loads [2-4]. Textile composites subjected to such impact load may cause invisible internal damages, which might render the composite material useless due to severely reduced structural integrity of the components [5]. Most textile composites absorb the impact energy through deformation and damage mechanisms; amongst them, delamination is considered as major failure mode [6,7]. Incorporation of fibers in the $z$-direction through the use of 3D structures and hybridization of high performance fibers in preforming are reported to be efficient ways to improve the impact performance of the textile composites [8].

Multilayer woven interlocked fabrics are distinctive class of 3D preforms, woven by selective interlacement and floats of yarns [9], which have been least explored to achieve interlocking of fabric layers during the weaving stage $[10,11]$. They provide the advantage of cost effective preform manufacture with control over layer interlocking density based on weave variations. These multilayer interlocked woven preforms with various architectures can be fabricated using variation of interlacements and floats in the structure. Orthogonal weave is a type of multilayer woven structure, where the yarns are arranged perpendicular to each other in $X, Y$, and $Z$ directions without any interlacements. Apart from the orthogonal multilayer structures, the multilayer fabrics are further categorized into angle interlocked and layer interlocked structures. In angle-interlock structures, warp yarns of each layer interlace with the weft yarns of the adjacent layers, while in layer-interlock structures warp yarns interlace the top and bottom layer of the fabric. Design and structure of the multilayer interlocked woven preform determine its performance properties.

Structure-property relation in terms of factor or index using both interlacement and float becomes critical especially for fabrics with multilayered structures, for which structural factors have not been applied yet. An attempt has been made to study the consequence of interlacement variations in multilayer woven structures on the impact behavior of composites reinforced with them. Nine different multilayer interlocked woven structures with varying interlacements have been developed to study the influence of interlacement. Interlacement index $(I)$ has been used to explain the influence of interlacements on the multilayer woven fabric properties [12]. 
Interlacement index is the ratio of number of interlacements in the given weave repeat to that of maximum possible contact field in the design given by Equation (1):

$$
I=\left(\frac{i_{w p}+i_{w f}}{R_{1} \cdot R_{2}}\right)
$$

where $i_{w p}$ and $i_{w f}$ are interlacements in warp and weft respectively; product of warp repeat $\left(R_{1}\right)$ and weft repeat $\left(R_{2}\right)$ of a woven design gives the maximum possible contact fields in the woven design. Further, damage area maps have been developed based on the post impacted specimen image analyses, to analyze the influence of interlacement on impact behavior of the composite materials.

\section{MATERIAL AND METHODS}

The 2-ply and 3-ply multilayer fabric samples were woven on 4 harness, flexible rapier automatic loom (Dornier), at $400 \mathrm{rpm}$ with $24 \mathrm{ends} / \mathrm{cm}$ and 12 picks $/ \mathrm{cm}$ setting. 5 meter length each of four varieties of Nylon 2-Ply fabrics (N2P1, N2P2, N2P3, and N2P4) along with five varieties of 3-ply fabrics (N3P1, N3P2, N3P3, N3P4, and N3P5) were woven for the present studies using high tenacity Nylon-6 filament yarn (96 Tex, fiber diameter $27.2 \mu \mathrm{m})$. These nine structures were chosen for the present study as these designs represent combined variations in the 2-layer \& 3-layer structures having layer interlock, angle-interlock, and orthogonal multilayer structures. Also they represent least to maximum interlaced design variations possible among the multilayer structures which can be easily formed on any weaving loom fitted with 4 harnesses (healds). The graphical representation of the woven design and the line diagrams of 2-ply and 3-ply multilayer woven structures are represented in the Figures 1 and 2. Among these multilayer structures $\mathrm{N} 2 \mathrm{P} 1, \mathrm{~N} 2 \mathrm{P} 2, \mathrm{~N} 2 \mathrm{P} 3, \mathrm{~N} 3 \mathrm{P} 1, \mathrm{~N} 3 \mathrm{P} 2$, and $\mathrm{N} 3 \mathrm{P} 3$ are the orthogonal structures, N3P4 and N3P5 are layer interlock structures where as N2P4 is an angle interlock structure. Nylon 6 plain woven (half the aerial density of multilayer fabric), was used as reference sample for comparison of results of the above mentioned multilayer samples. The general construction characteristics of the fabric samples made are provided in the Table 1, where $n_{1}, n_{2}$ denote ends/cm, picks/cm, $c_{1}, c_{2}$ represent warp, weft crimp \% values and $I$ is the interlacement index of the structure.

Composites were prepared with these preforms by hand-lay-up method using unsaturated polyester resin cured for one day at ambient temperature 

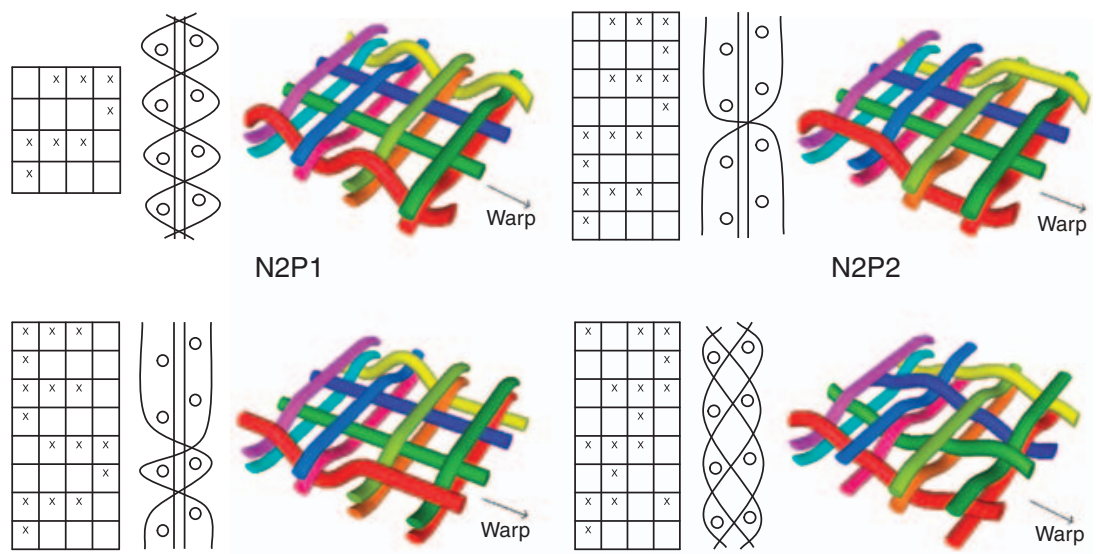

$\mathrm{N} 2 \mathrm{P} 3$
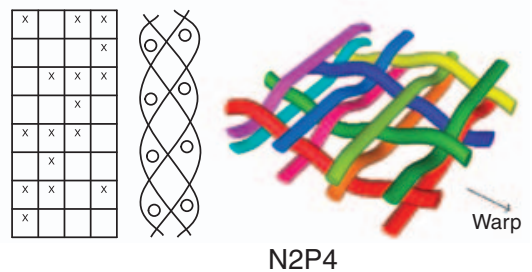

FIGURE 1. 2-Ply multilayer woven structures.
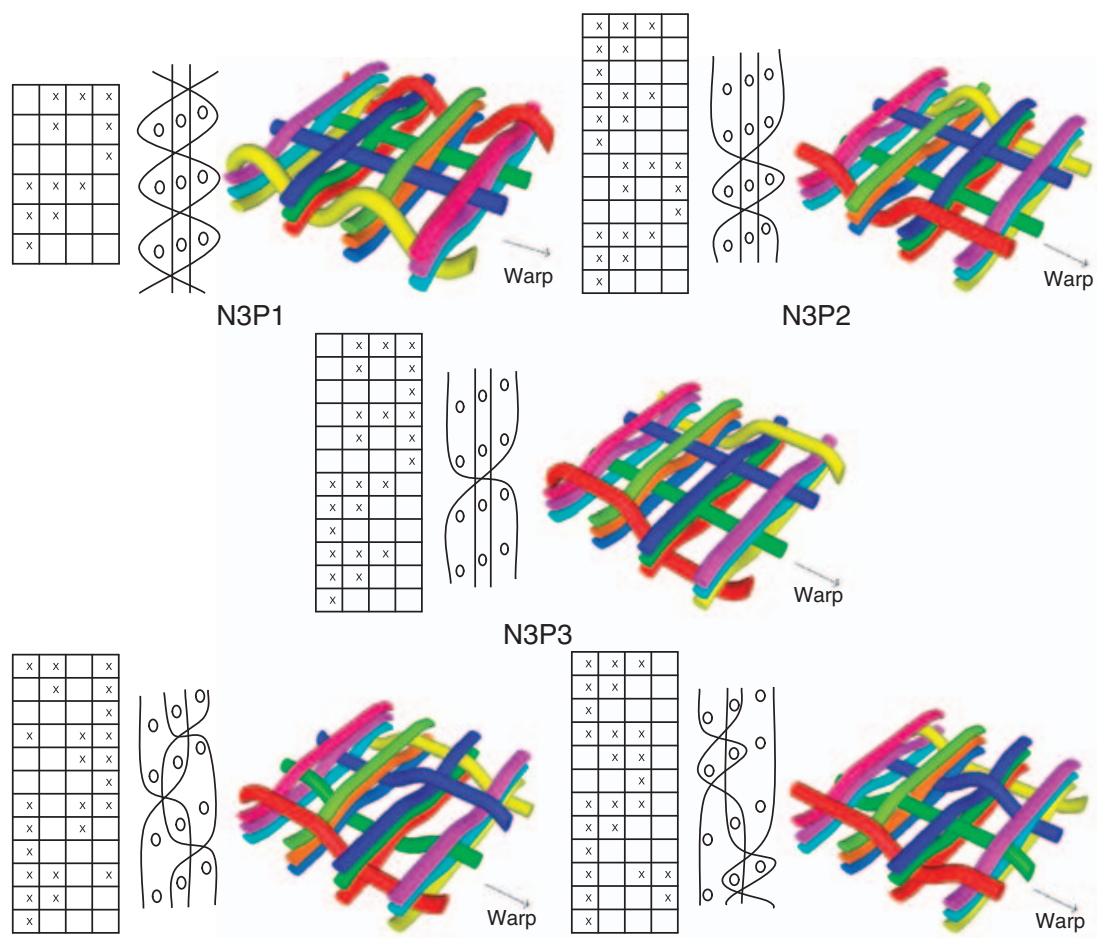

N3P4

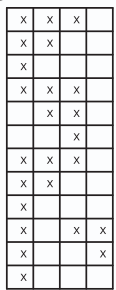

FIGURE 2. 3-Ply multilayer woven structures. 
Table 1. Multilayer woven perform properties.

\begin{tabular}{lcccccl}
\hline & $\begin{array}{c}n_{1} \times n_{2} \\
(/ \mathrm{cm})\end{array}$ & $\begin{array}{c}c_{1} \\
(\%)\end{array}$ & $\begin{array}{c}c_{2} \\
(\%)\end{array}$ & $\begin{array}{c}\text { Thickness } \\
(\mathrm{mm})\end{array}$ & $\begin{array}{c}\text { Aerial density } \\
\left(\mathrm{g} / \mathrm{m}^{2}\right)\end{array}$ & \multicolumn{1}{c}{$\boldsymbol{l}$} \\
\hline N2P1 & $24 \times 13$ & $7.8(6.4)$ & $3.6(2.3)$ & 1.12 & $432.6(2.8)$ & 1.25 \\
N2P2 & $23 \times 11$ & $6.9(9.3)$ & $3.2(3.8)$ & 1.18 & $411.4(3.1)$ & 1.125 \\
N2P3 & $23 \times 11$ & $5.3(8.2)$ & $2.1(2.9)$ & 1.20 & $407.6(5.3)$ & 1.125 \\
N2P4 & $24 \times 12$ & $4.3(3.8)$ & $2.6(3.2)$ & 1.25 & $412.2(4.7)$ & 1.00 \\
N3P1 & $25 \times 12$ & $6.3(7.6)$ & $3.1(3.0)$ & 1.22 & $422.2(2.9)$ & 1.0833 \\
N3P2 & $24 \times 12$ & $4.4(6.7)$ & $2.1(4.1)$ & 1.34 & $420.1(3.2)$ & 0.9583 \\
N3P3 & $24 \times 12$ & $5.6(7.8)$ & $3.0(1.9)$ & 1.32 & $438.5(2.5)$ & 1.00 \\
N3P4 & $24 \times 13$ & $6.5(3.9)$ & $4.0(3.3)$ & 1.27 & $436.8(1.4)$ & 0.9167 \\
N3P5 & $25 \times 12$ & $6.8(4.8)$ & $3.6(4.4)$ & 1.41 & $437.2(2.9)$ & 0.8333 \\
NP-control & $12 \times 6$ & $7.3(4.2)$ & $4.6(2.3)$ & 0.71 & $212.3(4.5)$ & 2.00 \\
\hline
\end{tabular}

Note: CV \% values are given within parenthesis.

Table 2. Properties of multilayer reinforced composites.

\begin{tabular}{lccc}
\hline & $\begin{array}{c}\text { Thickness } \\
(\mathrm{mm})\end{array}$ & $V_{f}$ & $\begin{array}{c}\text { Void } \\
(\%)\end{array}$ \\
\hline N2P1 & $1.62(4.8)$ & 0.31 & $2.46(3.6)$ \\
N2P2 & $1.61(2.4)$ & 0.32 & $2.35(4.8)$ \\
N2P3 & $1.63(4.5)$ & 0.28 & $1.65(3.4)$ \\
N2P4 & $1.64(3.8)$ & 0.30 & $1.73(6.1)$ \\
N3P1 & $1.65(2.3)$ & 0.28 & $2.97(7.5)$ \\
N3P2 & $1.64(3.1)$ & 0.27 & $2.29(4.3)$ \\
N3P3 & $1.64(4.2)$ & 0.28 & $1.84(3.6)$ \\
N3P4 & $1.65(4.0)$ & 0.28 & $1.90(5.3)$ \\
N3P5 & $1.63(3.8)$ & 0.32 & $2.55(6.8)$ \\
NP-control & $1.62(5.4)$ & 0.31 & $3.91(9.7)$ \\
\hline
\end{tabular}

Note: CV \% values are given within parenthesis.

with thickness spacer of $1.6 \mathrm{~mm}$. The physical properties of the laminates prepared are presented in Table 2. Fiber volume fraction $\left(V_{f}\right)$ of the composite was calculated using the Equation (2), with fiber density $\left(\sigma_{f}\right)$, composite density $\left(\sigma_{c}\right)$, data from density gradient tests along with weight (gsm) of fabric $\left(W_{f}\right)$, and composite $\left(W_{c}\right)$. Void (percentage) was estimated by image analysis using optical microscopy technique as per the method suggested by Purslow [13].

$$
V_{f}=\frac{W_{f} / \sigma_{f}}{W_{c} / \sigma_{c}}
$$




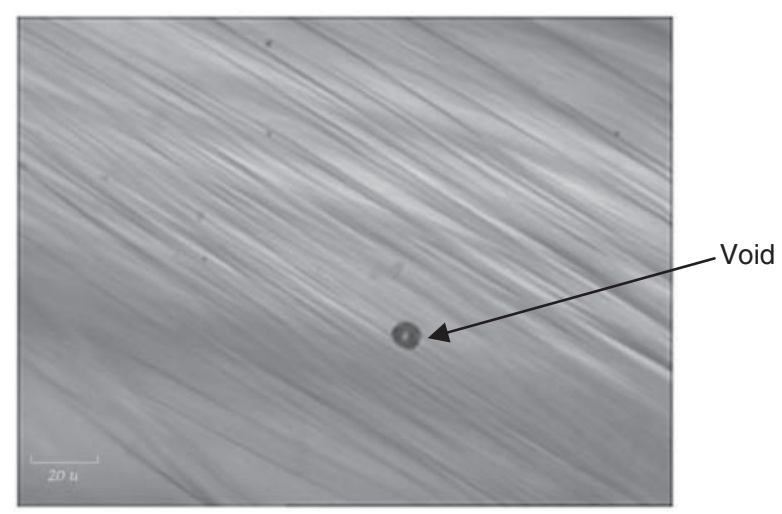

FIGURE 3. Void estimation by image analysis. Image of N3P3 composite $(40 \times)$.

Table 3. Composite tensile and flexural test results.

\begin{tabular}{lccccc}
\hline & \multicolumn{2}{c}{ Tensile strength (MPa) } & & \multicolumn{2}{c}{ Flexural strength (MPa) } \\
\cline { 2 - 3 } & Warp & Weft & & Warp & Weft \\
\hline N2P1 & $115.7(3.3)$ & $75.1(6.7)$ & & $48.5(2.1)$ & $26.6(3.9)$ \\
N2P2 & $119.3(4.1)$ & $68.5(2.9)$ & & $47.1(4.3)$ & $21.6(1.4)$ \\
N2P3 & $115.0(2.8)$ & $64.3(3.4)$ & & $54.7(3.2)$ & $33.6(4.1)$ \\
N2P4 & $111.2(4.9)$ & $63.8(2.1)$ & & $42.4(1.5)$ & $21.0(2.4)$ \\
N3P1 & $116.2(3.8)$ & $66.4(5.2)$ & & $39.6(3.3)$ & $31.0(2.1)$ \\
N3P2 & $114.8(4.3)$ & $64.9(3.7)$ & & $49.8(1.4)$ & $29.1(2.8)$ \\
N3P3 & $116.8(5.4)$ & $66.7(4.4)$ & & $50.1(2.9)$ & $31.7(3.5)$ \\
N3P4 & $116.0(4.2)$ & $66.9(2.4)$ & & $51.4(2.3)$ & $31.6(4.6)$ \\
N3P5 & $117.2(2.1)$ & $71.8(5.5)$ & & $51.1(2.1)$ & $30.0(4.2)$ \\
NP-control & $108.3(6.3)$ & $63.1(8.2)$ & & $50.1(7.6)$ & $30.6(5.2)$ \\
\hline
\end{tabular}

Note: CV \% values are given within parenthesis.

In this method 50 images of each composite were captured using Leica microscope $(40 \times)$ fitted with digital camera and representative image of the N3P3 reinforced composite sample is given in Figure 3. The images were analyzed for presence of void and average void was calculated from the ratio of total void area to the area of composite.

\section{Composite Mechanical Properties}

The tensile properties of the composite samples were evaluated as per ASTM D 3039 standard on Instron universal tester. Flexural tests on the composites were carried out on the same Instron tester as the ASTM 
Table 4. Low velocity impact test results.

\begin{tabular}{|c|c|c|c|c|c|c|}
\hline & \multicolumn{2}{|c|}{$5 \mathrm{~J}$} & \multicolumn{2}{|c|}{$15 \mathrm{~J}$} & \multicolumn{2}{|c|}{$25 \mathrm{~J}$} \\
\hline & $\begin{array}{l}\text { Max. load } \\
\quad(k N)\end{array}$ & $\begin{array}{l}\text { Total energy } \\
\text { (J) }\end{array}$ & $\begin{array}{l}\text { Max. load } \\
\quad(k N)\end{array}$ & $\begin{array}{c}\text { Total energy } \\
\text { (J) }\end{array}$ & $\begin{array}{l}\text { Max. load } \\
\quad(k N)\end{array}$ & $\begin{array}{c}\text { Total energy } \\
\text { (J) }\end{array}$ \\
\hline N2P1 & 1.47 & 5.38 & 2.13 & 10.72 & 2.27 & 11.43 \\
\hline N2P2 & 1.43 & 5.40 & 1.93 & 10.78 & 2.17 & 10.66 \\
\hline N2P3 & 1.42 & 5.37 & 1.98 & 9.37 & 2.14 & 10.13 \\
\hline N2P4 & 1.42 & 5.13 & 2.00 & 9.93 & 2.10 & 10.65 \\
\hline N3P1 & 1.44 & 5.47 & 2.01 & 11.05 & 2.12 & 10.08 \\
\hline N3P2 & 1.40 & 5.38 & 1.86 & 9.91 & 1.93 & 10.09 \\
\hline N3P3 & 1.42 & 5.25 & 2.01 & 12.12 & 1.97 & 11.03 \\
\hline N3P4 & 1.40 & 5.55 & 1.76 & 10.08 & 1.88 & 10.59 \\
\hline N3P5 & 1.36 & 5.44 & 1.71 & 10.67 & 1.85 & 10.20 \\
\hline NP-control & 1.30 & 6.02 & 1.32 & 10.44 & 1.62 & 10.17 \\
\hline
\end{tabular}

Note: $\mathrm{CV} \%$ values $<3$.

Standard D 790. Table 3 provides the tensile and flexural tests results conducted on the composite samples.

Low velocity impact drop weight tests with semi-spherical indenter $(2.2 \mathrm{~kg})$ were conducted on the composites at three different impact energy levels of $5 \mathrm{~J}, 15 \mathrm{~J}$, and $25 \mathrm{~J}$ using a DYNATUP GRC model with 830-I data acquisition software. Three tests were conducted on the multilayer composites samples of size $9 \mathrm{~cm} \times 9 \mathrm{~cm}$ at each impact energy level.

\section{RESULTS AND DISCUSSIONS}

Impact result shows interesting observations with multilayer reinforced composites. Table 4 provides the impact test results for three levels of impact energy. Figure 4 presents the select images of the composite samples under study subjected to impact test at the $5 \mathrm{~J}, 15 \mathrm{~J}$, and $25 \mathrm{~J}$ impact energy levels. It can be observed from the impacted specimens that at $5 \mathrm{~J}$ impact energy the control sample shows distinct fiber failure while the multilayer textile composite (N3P3) has absorbed the impact energy without fiber damage. At $15 \mathrm{~J}$ and $25 \mathrm{~J}$ impact energy, both control and multilayer samples display fiber failure and larger extent of damage has been observed with the control sample. Figures 5-7 illustrate the impact performance curves (Load-TimeEnergy) for these composite samples obtained from the instrumented impact test at $5 \mathrm{~J}, 15 \mathrm{~J}$, and $25 \mathrm{~J}$ impact energy levels respectively. Figure 8 represents a typical impact curve which has been used to explain the impact behavior of these multilayer composite samples. 


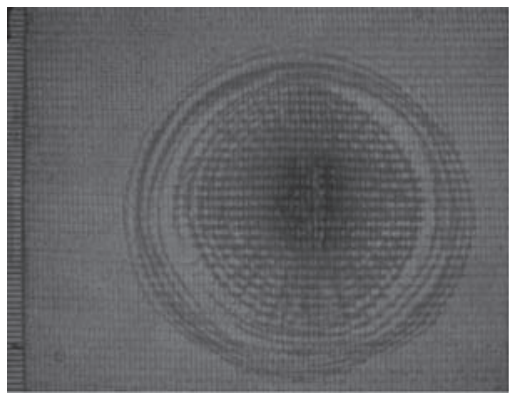

NP-Control (5J)

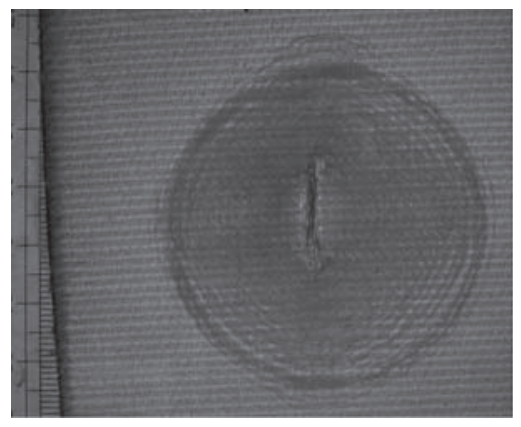

N2P1 (15J)

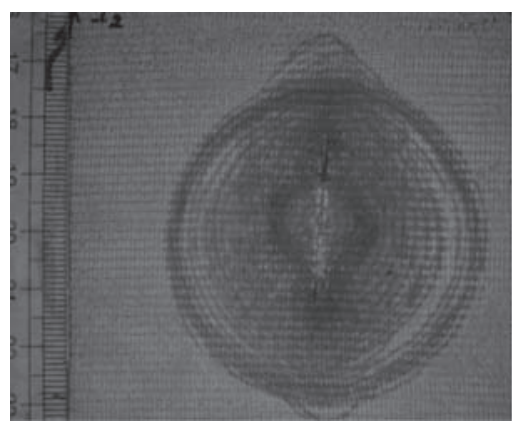

NP-Control (24.4J)

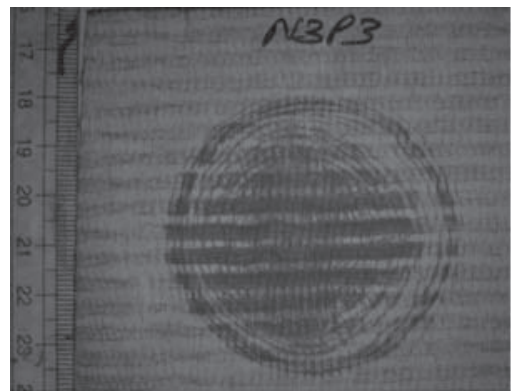

N3P3 (5J)

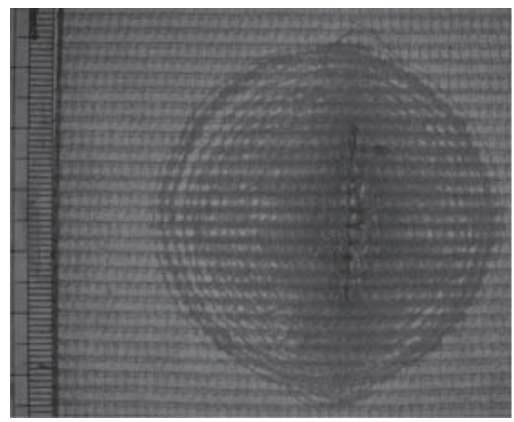

N3P1 (15J)

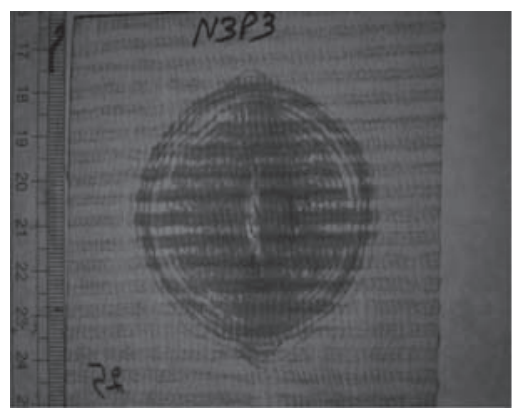

N3P3 (24.4J)

FIGURE 4. Images of composites impacted.

Multilayered structure of the reinforcement has significant influence on the impact performance of the composites under investigation, with all the multilayered composite samples performing better than the control specimen at both impact energy levels. Figure 8 represents a typical impact curve obtained from instrumented impact tester. In textile reinforced composites 


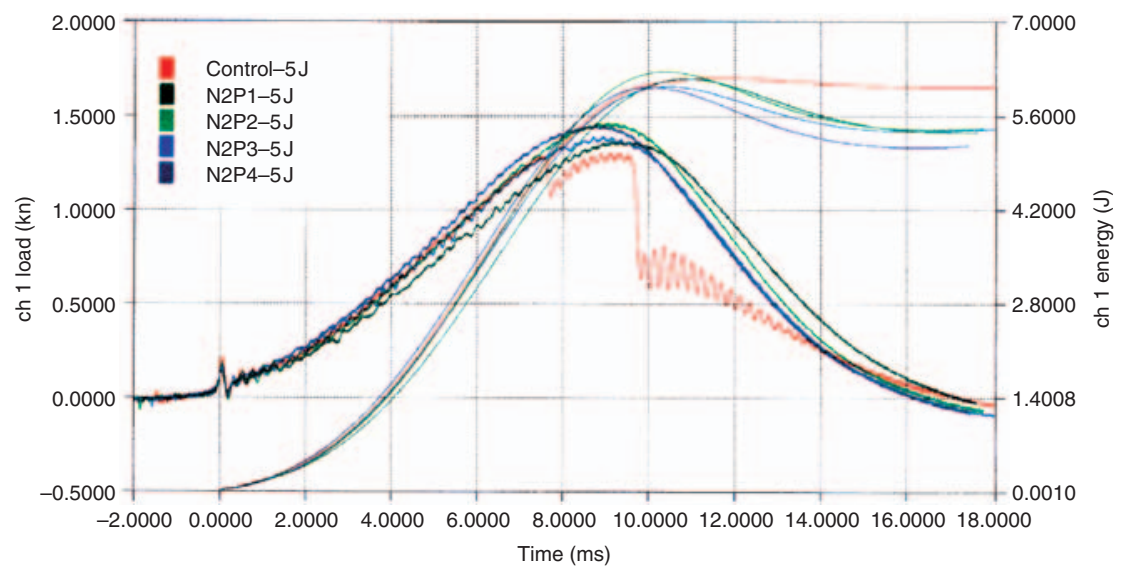

FIGURE 5. Impact plot of $5 \mathrm{~J}$ on 2-ply multilayered composite specimens.

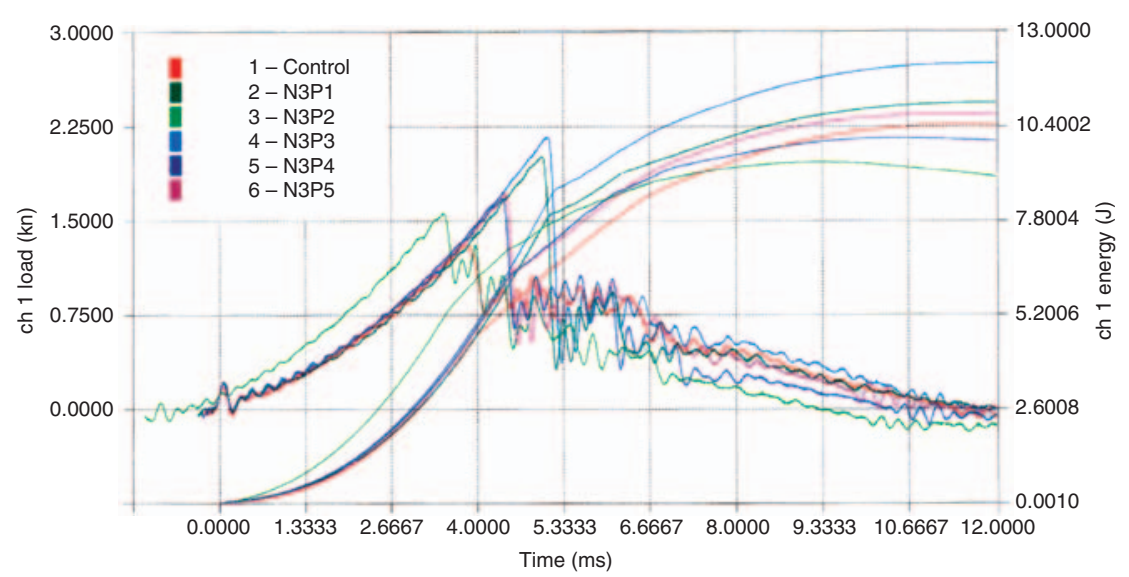

FIGURE 6. Impact plot of $15 \mathrm{~J}$ on 3-ply multilayered composite specimens.

there is very little plastic deformation and impact energy is initially absorbed through elastic deformation till a threshold. The maximum load point (MLP) or this threshold value is the peak impact load that a laminate can tolerate before undergoing major damage. At the MLP, a major fiber breakage occurs through the laminate thickness. The maximum load $(P m)$ and the required energy $(\mathrm{Em})$ at the maximum load are shown in Figure 8.

From the impact load-time curves it can be seen that the 2-ply NP-control sample has failed catastrophically distinctly at maximum load point, while 


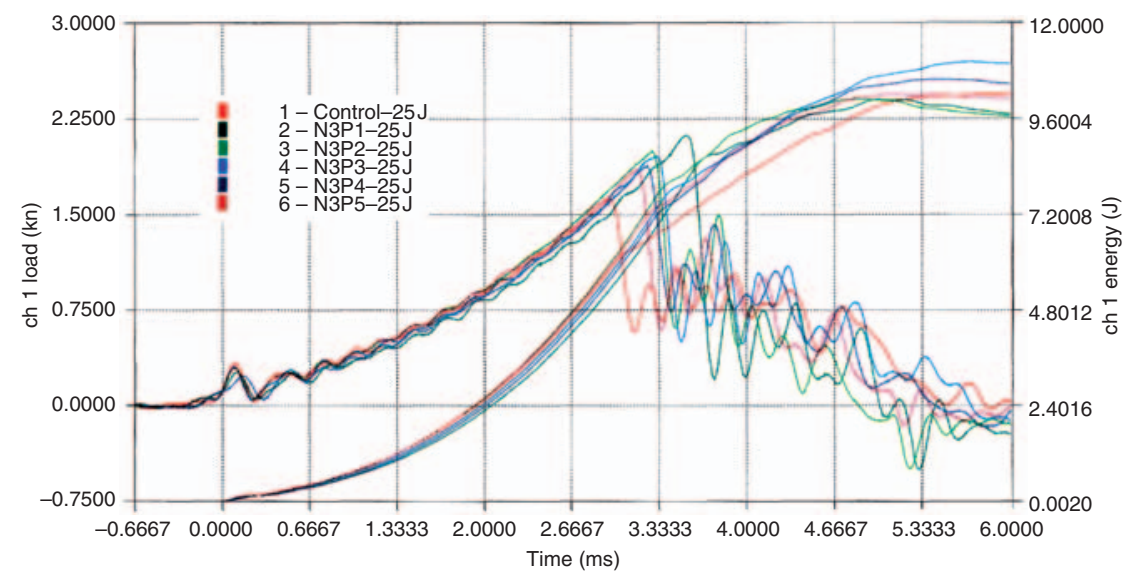

FIGURE 7. Impact plot of $25 \mathrm{~J}$ on 3-ply multilayered composite specimens.

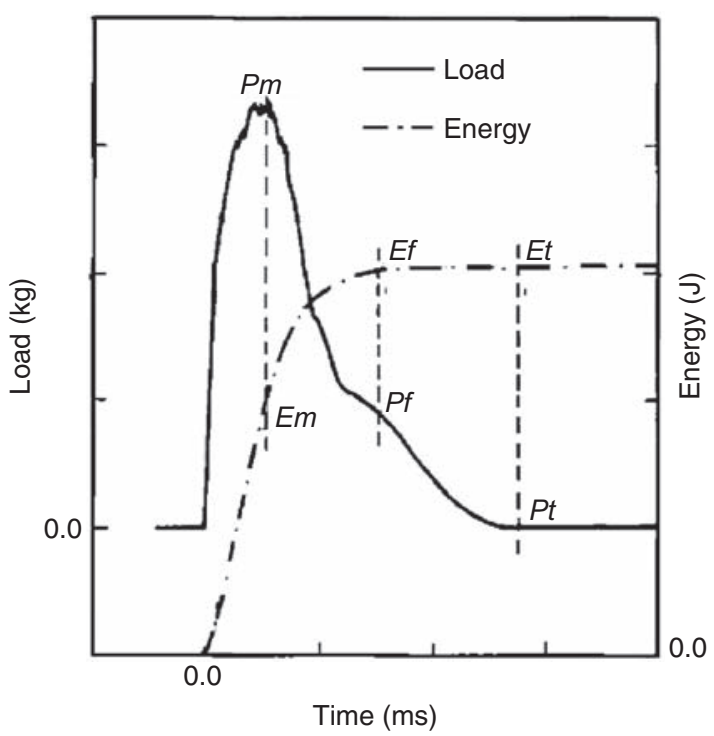

FIGURE 8. Typical instrumented impact curve.

all multilayer woven interlock reinforced composites exhibit damage tolerance at $5 \mathrm{~J}$ impact energy (Figure 5). At $15 \mathrm{~J}$ and $25 \mathrm{~J}$ impact energy levels, it has been observed that all the multilayer composite samples have displayed superior peak impact load for fiber failure compared to the 


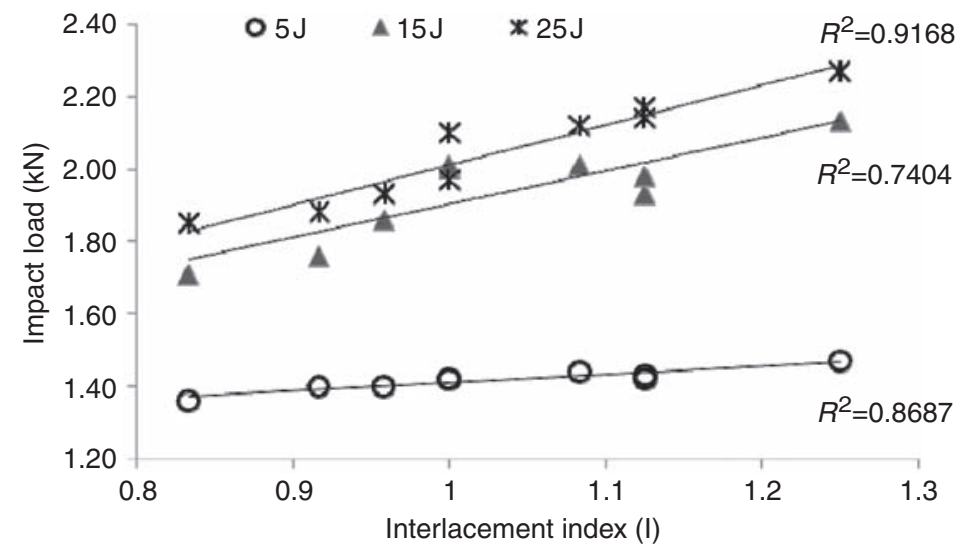

FIGURE 9. Interlacement index vs max. impact load for multilayer composites.

control samples (Figures 6 and 7). N2P1 and N3P1 composite samples have shown higher impact strength with maximum impact load for failure whereas $\mathrm{N} 2 \mathrm{P} 2$ and $\mathrm{N} 3 \mathrm{P} 1$ samples have demonstrated higher impact resistance through absorption of maximum impact energy at $15 \mathrm{~J}$ impact. Similar to the $15 \mathrm{~J}$ impact behavior, N2P1 and N2P2 composite samples have shown higher impact strength with maximum impact load for failure at $25 \mathrm{~J}$ impact energy, while $\mathrm{N} 2 \mathrm{P} 1$ and $\mathrm{N} 3 \mathrm{P} 3$ samples have demonstrated higher impact resistance through absorption of maximum impact energy at $25 \mathrm{~J}$ impact.

A plot of interlacement index with maximum impact load to failure of multilayer textile composites under investigation, infers that impact strength of these composite materials increase with increased interlacements in the woven reinforcement as shown in the Figure 9. Higher interlacement indexed N2P1 composite demonstrates maximum impact load to failure and similarly least impact strength is displayed by N3P5 reinforced composite having least interlacement index (0.8333). Overall it could be assessed that the orthogonal structures have performed superior, layer interlock structures have inferior impact property whereas the angle interlock structure (N2P4) has almost similar impact performance as those of orthogonal structures among the multilayer structures presently studied for impact behavior.

Post impacted specimens were subjected to image processing technique using Image $\mathbf{J}^{\circledR}$ software to analyze the damage area during impact event. A typical impacted damage area map is represented by Figure 10, which illustrates the fiber failure, interphase or interface failure, and matrix failure regions in the impact damage traced image. Table 5 presents the segregated 


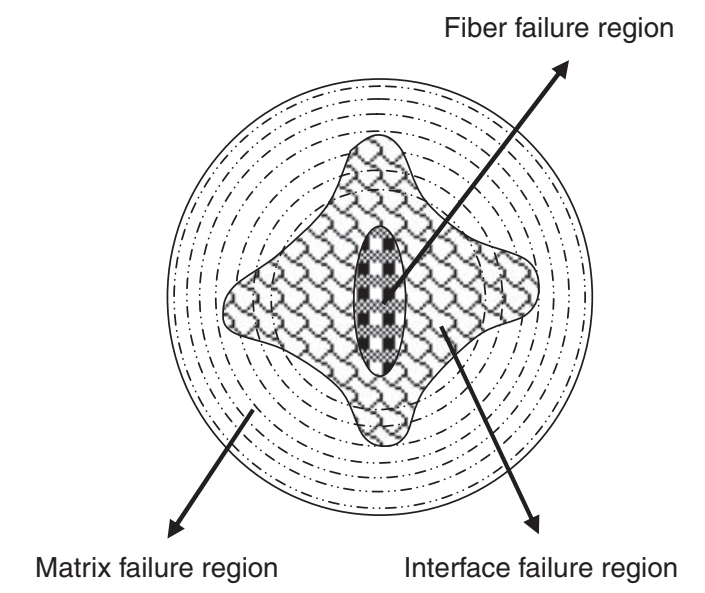

FIGURE 10. Traced image displaying damage area map in impacted specimen.

Table 5. Impacted specimen damage area $\left(\mathrm{cm}^{2}\right)$.

\begin{tabular}{lllllll}
\hline & \multicolumn{2}{c}{ Fiber failure } & & \multicolumn{3}{c}{ Interphase failure } \\
\cline { 2 - 3 } Composite & 15J & 25J & & 5J & 15J & 25 J \\
\hline N2P1 & 0.31 & 0.58 & & 4.92 & 5.45 & 6.44 \\
N2P2 & 0.40 & 0.63 & & 4.87 & 4.90 & 5.37 \\
N2P3 & 0.42 & 0.64 & & 4.69 & 4.79 & 5.33 \\
N2P4 & 0.54 & 0.66 & & 4.47 & 4.66 & 5.00 \\
N3P1 & 0.53 & 0.62 & & 4.51 & 4.64 & 5.28 \\
N3P2 & 0.59 & 0.64 & & 4.23 & 4.45 & 4.71 \\
N3P3 & 0.49 & 0.63 & & 4.46 & 4.67 & 5.29 \\
N3P4 & 0.62 & 0.69 & & 4.21 & 4.29 & 4.18 \\
N3P5 & 0.72 & 0.72 & & 3.86 & 4.10 & 4.04 \\
NP-control & 1.41 & 0.77 & 3.24 & 4.09 & 7.28 \\
\hline
\end{tabular}

areas of the impacted specimens into these regions and Figures 9 and 10 illustrate the influence of reinforcement structure (interlacement index) on the damage area of the impacted composite samples.

It can be seen from Figure 11 that increased interlacement in the multilayered reinforcement results in decreased fiber failure zone in the composite. Higher interlacement in the structure increases the load transfer efficiency of the reinforcement through these interlacements which act as joints in the structure. Hence higher the interlacement lower would be the fiber failure region. 


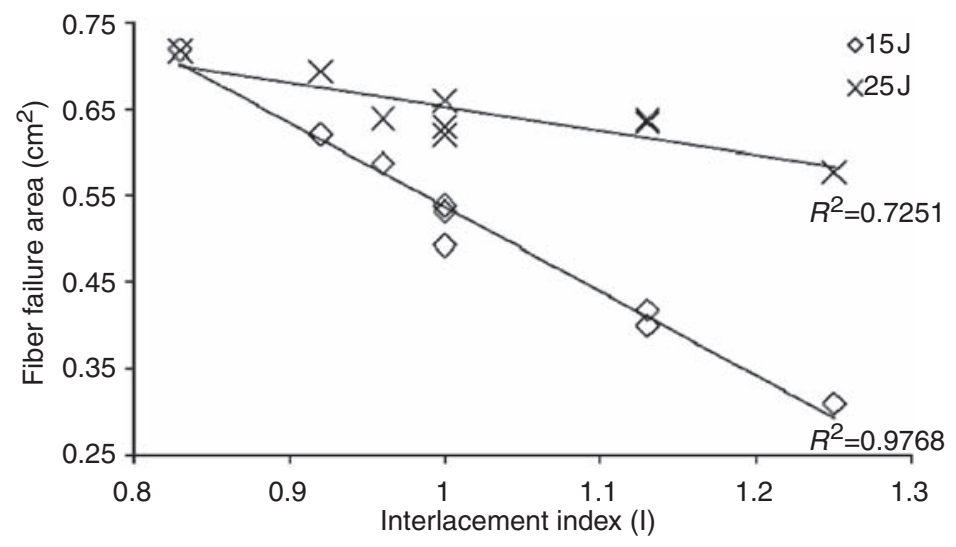

FIGURE 11. Fiber failure area vs interlacement index for impacted multilayer composites.

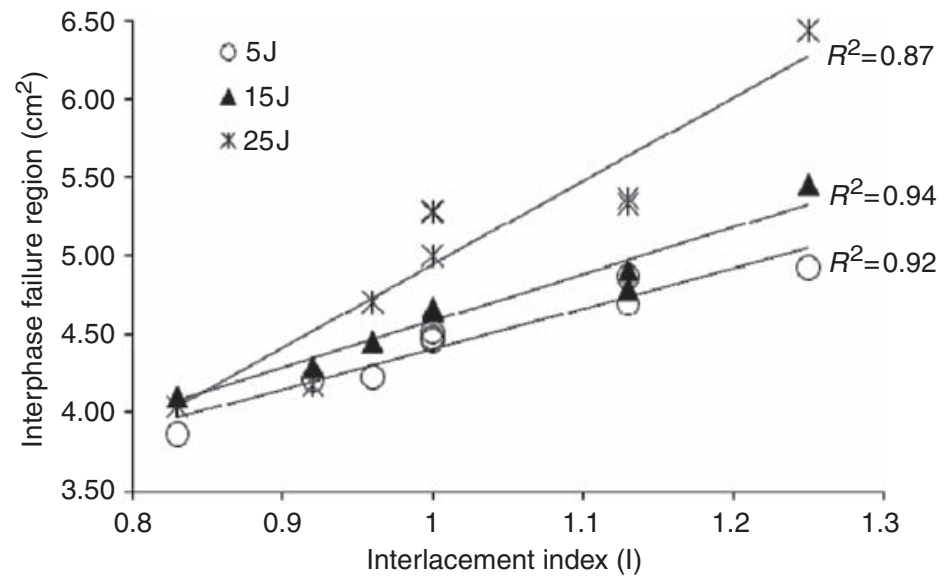

FIGURE 12. Interphase failure area vs interlacement index for multilayer composites.

Figure 12 shows the influence of reinforcement structure in terms of interlacement index on the interphase failure region. It can be assessed that increased interlacements in the multilayer structure cause higher interphasial failure regions in the composites which can also be attributed to better dissipation of load in the multilayer structure through interlacement points. Also lower interlacement in the structure would result in lack of load transferability in the composite which could further result in stress accumulation at the zone of impact. Thus higher fiber failure are effected as evinced by the results of layer interlocked structures N3P4 and N3P5 reinforced composites. 
During an impact event, the interlacements in the reinforcement act as binding points which transmit the impact load from one fiber to other. A higher interlacement index of the structure increases the ability of the composite to withstand higher load with better dissipation of the impact load, thus reducing the fiber failures in the composite material as evident from the Figures 9 and 11. During such impact load dissipation, fibers tend to deform from their position thereby causing interphasial debonding with the matrix thus resulting in debonding with the matrix which absorb significant amount of impact energy to create failure regions. Hence with increased interlacement in the reinforcement, lower would be the fiber failure and higher would be the interphasial failures as observed from the results of the impact behavior of multilayer composites in this study (Figures 9, 11, and 12). With better understanding of important role played by the interlacement in the multilayer woven composites, the task of designing impact damage tolerant structure would be much helpful.

\section{CONCLUSIONS}

Multilayer structures have significant influence on the impact behavior of composites reinforced with them. Interlacements in the multilayer reinforcement has been represented by the Interlacement index (I), to correlate the structural geometry on the impact performance. Higher interlacement index of the reinforcement results in better impact strength of the composite material. Damage area analysis through image processing has been successively tried to understand the influence of interlacement on impact performance of the multilayer reinforced composites. Increased interlacements in the multilayer structure cause lower fiber failure regions and higher interphasial failure regions in the composites, which are due to better dissipation of load in the multilayer structure through interlacement points.

\section{REFERENCES}

1. Hearle, J.W.S. (1994). Textiles for Composites a Business Opportunity for the 21st Century Part I, Textile Horizons, 14(6): 12-15.

2. Richardson, M.O.W. and Wisheart, M.J. (1996). Review of Low-velocity Impact Properties of Composite Materials, Composites: Part A, 27A: 1123-1131.

3. Cantwell, W.J. and Morton, J. (1991). The Impact Resistance of Composite Materials - A Review, Composites, 22(5): 347-362.

4. Sevkat, E., Liaw, B., Delale, F. and Raju, B.B. (2009). Drop-weight Impact of Plain-woven Hybrid Glass-Graphite/Toughened Epoxy Composites, Composites:

Part A, 40(8): 1090-1110. 
5. Abrate, S. (1991). Impact on Laminated Composite Materials, Applied Mechanics Reviews, 44(4): 155-190.

6. Elder, D.J., Thomson, R.S., Nguyen, M.Q. and Scott, M.L. (2004). Review of Delamination Predictive Methods for Low Speed Impact of Composite Laminates, Composite Structures, 66(1-4): 677-683.

7. Donadon, M.V., Iannucci, L., Falzon, B.G., Hodgkinson, J.M. and de Almeida, S.F.M. (2008). A Progressive Failure Model for Composite Laminates Subjected to Low Velocity Impact Damage, Computers \& Structures, 86(11-12): 1232-1252.

8. Padaki, N.V., Sugun, B.S., Alagirusamy, R., Deopura, B.L. and Fanguiero, R. (2008). Low Velocity Impact Behavior of Textile Reinforced Composites, Indian Journal of Fiber and Textile Research, 33(2): 189-202.

9. Adanur, S. and Andrew Tam, C. (1997). On-machine Interlocking of 3D Laminate Structures for Composites, Composites: Part B, 28B: 497-506.

10. Hu, H. (2000). Comparison Between Laminated and Integrated Glass Fiber Reinforced Plastics, Materials \& Design, 21: 461-464.

11. $\mathrm{Hu}, \mathrm{H}$. and Zhilli, Z. (2002). Tensile Behavior of 3D Woven Composites by Using Different Fabric Structures, Materials \& Design, 23(7): 671-674.

12. Padaki, N.V., Alagirusamy, R., Deopura, B.L. and Fanguiero, R. (2009). Studies on Preform Properties of Multilayer Interlocked Woven Structures Using Fabric Geometrical Factors, Journal of Industrial Textiles, 39(4): 327-346.

13. Purslow, D. (1984). On the Optical Assessment of the Void Content in Composite Materials, Composites, 15(3): 207-210.

\section{BIOGRAPHY}

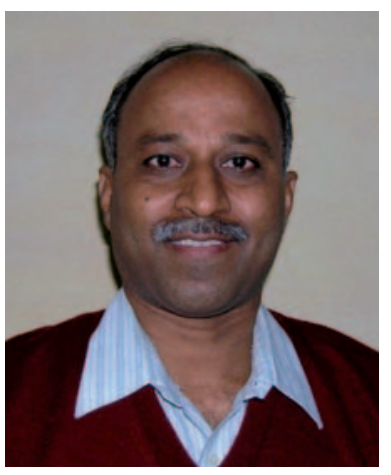

Mr Alagirusamy Ramasamy is currently working as a Professor in the Department of Textile Technology at the Indian Institute of Technology, Delhi (IIT Delhi), India. He completed his $\mathrm{PhD}$ from Georgia Institute of Technology, Atlanta, USA in 1994, in the field of textile preforming for composite applications using thermoplastic powder coated carbon towpregs. He has published more than 50 research articles in international journals and conferences. He has also contributed book chapters and monograms in the area of textile structures used in composite applications. His research areas of interest are textile performing for composites, hybrid yarn development for thermoplastic composites, natural fiber composites and structure property relations in spun yarns. 